\title{
Flame Extinction of Spherical PMMA in Microgravity: Effect of Fuel Diameter and Conduction
}

\author{
Chuanjia Wu ${ }^{1,2} \cdot$ Peiyi Sun ${ }^{3} \cdot$ Xiuzhen Wang ${ }^{1,2} \cdot$ Xinyan Huang ${ }^{3}$ (D) Shuangfeng Wang ${ }^{1,2}$
}

Received: 20 April 2020 / Accepted: 30 August 2020 / Published online: 28 September 2020

(C) Springer Nature B.V. 2020

\begin{abstract}
A series of experiments were conducted in the 3.6-s microgravity drop tower and normal gravity to investigate the effect of solid fuel curvature, conduction, and reradiation on the flame extinction of spherical polymethyl methacrylate (PMMA). In the semi-quiescent microgravity environment, flame extinction was observed if the PMMA diameter was larger than $40 \mathrm{~mm}$, because of a smaller flame conductive heating in larger diameter (i.e., the curvature effect). Compared to the droplet combustion with a low evaporation point and fast heat convection in the liquid phase, the solid fuel has a high pyrolysis point and large transient heat conduction. Thus, the large surface reradiation effectively cools down the fuel surface to promote extinction. Also, as the initial burning duration increases, the conductive cooling into the solid fuel decreases, which delays or prevents the flame extinction in microgravity. The extinction criterion for microgravity flame is explained by the critical mass flux and mass-transfer number. This work helps to understand the curvature effect of solid fuel on flame extinction and the material fire safety in the microgravity spacecraft environment.
\end{abstract}

Keywords Spacecraft fire $\cdot$ Plastic fuel $\cdot$ Drop tower $\cdot$ Curvature effect $\cdot$ Heat conduction

\section{NomenclatureSymbols}

A $\quad$ area $\left(\mathrm{mm}^{2}\right)$

$B \quad$ mass-transfer number $(-)$.

$c_{g} \quad$ specific heat of gas $(\mathrm{J} / \mathrm{kg} / \mathrm{K})$.

$c_{p} \quad$ specific heat of solid $(\mathrm{J} / \mathrm{kg} / \mathrm{K})$.

$d \quad$ diameter (mm).

$d_{e q} \quad$ equivalent diameter $(\mathrm{mm})$.

Electronic supplementary material The online version of this article (https://doi.org/10.1007/s12217-020-09829-5) contains supplementary material, which is available to authorized users.

Xinyan Huang

xy.huang@polyu.edu.hk

$\triangle$ Shuangfeng Wang

sfwang@imech.ac.cn

1 Key Laboratory of Microgravity, Institute of Mechanics, Chinese Academy of Sciences, Beijing, China

2 School of Engineering Science, University of Chinese Academy of Sciences, Beijing, China

3 Research Center for Fire Engineering, Department of Building Services Engineering, The Hong Kong Polytechnic University, Hong Kong, China
FSR flame stand-off ratio $\left(d_{f} / d_{s}\right)$.

$\Delta h_{c} \quad$ heat combustion $(\mathrm{J} / \mathrm{kg})$.

$\Delta h_{p y} \quad$ enthalpy of pyrolysis $(\mathrm{J} / \mathrm{kg})$.

$L \quad$ characteristic length ( $\mathrm{mm})$.

$m \quad$ mass (g).

$\dot{m}^{\prime \prime} \quad$ mass flux $\left(\mathrm{g} / \mathrm{m}^{2} / \mathrm{s}\right)$.

$k \quad$ heat conductivity $(\mathrm{W} / \mathrm{m}-\mathrm{K})$.

$\dot{q}^{\prime \prime} \quad$ conductive heat flux $\left(\mathrm{kW} / \mathrm{m}^{2}\right)$.

$r \quad$ sphere radius (mm).

$t$ time (s).

$t_{0} \quad$ initial burning duration (s).

$T$ temperature (K).

$V \quad$ Volume $\left(\mathrm{mm}^{3}\right)$

$X_{r} \quad$ fraction of flame radiation (-).

$Y_{\mathrm{O}_{2}} \quad$ mass fraction of oxygen (-).

\section{Greeks}

$\delta \quad$ depth (mm).

$\varepsilon$ radiative emittance $(-)$.

$\eta \quad$ ratio coefficient (-)

$\kappa$ fuel curvature, $1 / r\left(\mathrm{~mm}^{-1}\right)$.

$v$ air to fuel stoichiometric mass ratio.

$\rho$ density $\left(\mathrm{kg} / \mathrm{m}^{3}\right)$.

$\sigma \quad$ Stefan-Boltzmann constant $\left(\mathrm{W} / \mathrm{m}^{2} / \mathrm{K}^{4}\right)$.

$\Phi$ thermocouple diameter (mm). 


\begin{tabular}{ll}
\multicolumn{2}{l}{ Subscripts } \\
$\infty$ & ambient. \\
cond & conduction. \\
crt & critical value \\
$f$ & flame. \\
in & in-depth net net heat flux \\
py & pyrolysis. \\
$r$ & radiation. \\
$r e$ & reradiation. \\
$s$ & solid or surface. \\
$s h$ & shell.
\end{tabular}

\section{Introduction}

Fire remains a significant risk for spaceflight that merits research for future flights, especially with the prosperous application of light polymer materials in the spacecraft (Friedman 1996; Bobola and Pate 2011; Huang et al. 2020). Spacecraft fire safety issues started receiving researchers' attention from the early $1907 \mathrm{~s}$. Since then, great efforts have been made to investigate the mechanism of flame spread, extinction, flammability, and the fire performance on many types of materials, such as polymers, electrical wires, and fabrics (Ikeda 2018; Nagachi et al. 2019; Thomsen et al. 2019. With the active and consistent international research collaborations, the understanding of microgravity fire dynamics has been continuously improved (Ross 2001; Urban et al. 2018). In addition to providing the direct fire-safety strategy for spacecraft, the microgravity experiment of fire researches achieved the simple combustion environment to eliminate the buoyancy effect, which benefits the fundamental combustion research. The burning of spherical fuels with a spherical flame can be considered as the one-dimensional (1-D) combustion system by diminishing buoyancy and natural convection (Mikami et al. 2018a; Mikami et al. 2018b; Vang and Shaw 2020). This 1-D combustion system can provide ideal conditions for understanding the effect of the curvature and geometry on combustion characteristics, especially for the liquid droplet combustion and with the classical d-square law (Law 1982; Dietrich et al. 2014).

The burning of a solid polymer sphere is similar to the droplet combustion except for the flame standoff ratio FSR and the temperature in the condensed-phase (Raghunandan and Mukunda 1977). Specifically, the pyrolysis temperature of solid polymers $\left(>300^{\circ} \mathrm{C}\right)$ is much higher than the evaporation point of most liquid fuels. The solid fuel temperature will continue to increase above the pyrolysis point, resulting in large surface reradiation (Bhattacharjee et al. 2017; Olson and Ferkul 2017). Moreover, the conductive heat flux into the solid interior is transient due to transient temperature gradient and smaller conductivity, which is different from the semi-uniform temperature inside the liquid droplet due to the large convective heat transfer. Both heat losses of surface reradiation and solid conduction will affect the microgravity flame extinction on solid fuels. Yang et al. (2000) studied the burning behavior of the PMMA spheres whose diameters were less than $6.4 \mathrm{~mm}$ at a reduced-gravity environment. They found that the transient diameter of the PMMA exhibited two distinct periods: the square of the diameter remains constant firstly and then linearly decreased with time. Johnston et al. (2017) have measured the local burning rate of PMMA spherical shell samples at different oxygen concentrations. Migita et al. (2020) used a low-pressure environment to achieve the pseudo-1-D combustion system of PMMA. Endo et al. (2020) reported the result of the PMMA sphere aboard the International Space Station and developed a model to illustrate flame growth and extinction. Except for representative fuel PMMA; $\mathrm{Hu}$ et al. (2012) have investigated the burning behavior of spherical methenamine $\left(\mathrm{C}_{6} \mathrm{H}_{12} \mathrm{~N}_{4}\right)$ during the transition from normal-gravity to reduced-gravity. Recently, Sun et al. (2020) showed that the burning rate constant of polyethylene droplet is much larger than those of liquid hydrocarbon due to bubbling and fuel ejection.

The planar solid fuel, as an extreme type of sphere, has been studied extensively (De Ris 1969; Williams 1977; Fujita 2015). As the mass flux of spherical solid fuels is inversely proportional to diameter in a quiescent environment (Raghunandan and Mukunda 1977), several microgravity experimental studies have shown that the flame cannot spread over thick PMMA in a quiescent environment (Bhattacharjee and Altenkirch 1991; West et al. 1996; Takahashi et al. 2002; Bhattacharjee et al. 2003; Zhu et al. 2019). Thus, there could be a critical (maximum) diameter for the PMMA sphere to maintain the flame. Nevertheless, the curvature effect is mostly studied with cylindrical fuels (Delichatsios et al. 2000; Olson and Hirsch 2011; Link et al. 2018; Wu et al. 2020). So far, there are limited studies on the effect of solid conduction and surface radiation on the extinction of spherical solid fuels.

To further illustrate the effect of solid conduction and surface radiation on the extinction of spherical solid fuels, PMMA spheres with different diameters $(10-40 \mathrm{~mm})$ were tested in a microgravity environment. As a reference, the burning behaviors, heat conduction, and temperature profile of the PMMA sphere in normal gravity are quantified and compared.

\section{Experiments Setup}

\section{Microgravity Experiments}

The microgravity experiments were conducted in the Chinese Academy of Science's $3.6 \mathrm{~s}$ Beijing drop tower with a $10^{-3} \mathrm{~g}$ gravity level (Zhang et al. 2011; Wang et al. 2015).The schematic of the microgravity experiments is shown in Fig. 1(a). The PMMA spheres diameters varied from $10 \mathrm{~mm}$ to $40 \mathrm{~mm}$, where the minimum diameter is greater than the previous 


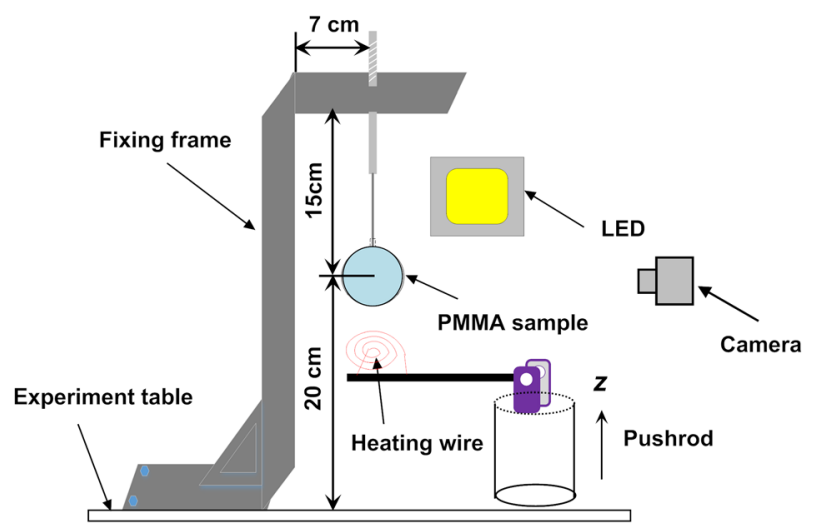

(a)

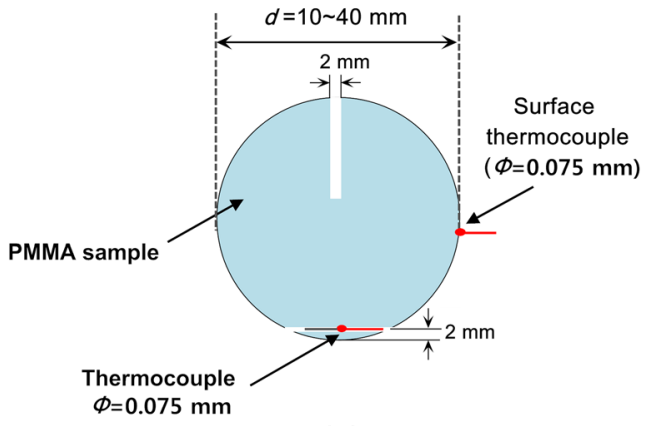

(b)

Fig. 1 (a) The schematic of the microgravity drop-tower experiment. (b) The detailed position of thermocouple in normal-gravity experiments

research (Yang et al. 2000). The tested PMMA spheres were burnished from the commercial cast PMMA plane. A K-type thermocouple (Omega Engineering Inc), with $0.075 \mathrm{~mm}$ bead head diameter, was threaded through a hole beneath $1 / 4 d$ of the sphere surface to measure the solid phase temperature, where the hole with a diameter of $0.05 \mathrm{~mm}$ was drilled during manufacturing. Besides, a steel rod was installed inside the sphere to fix the test sample. The distances between the PMMA sphere and the table and the fixing frame are $20 \mathrm{~cm}$ and $7 \mathrm{~cm}$ to reduce their influence on the flame. The ignition was achieved by a spiral heating $\mathrm{Ni}-\mathrm{Cr}$ wire. After ignition, the heating wire would be moved down immediately to avoid the disturbances on further combustion.

A GoPro Hero7 digital camera with a resolution of 1920 by 1080 at 120 fps was applied to record the burning process. In addition, a LED backlight system was set at the opposite side of the digital camera and flashed at $1 \sim 1.5 \mathrm{~Hz}$ frequency to illuminate both the outline and flame of the sphere. Experiment apparatuses were installed inside an enclosed capsule with $1 \mathrm{~m}^{3}$ void space, where the test environment is in a normal atmosphere. The sufficient inner space of the capsule makes it reasonable to ignore the oxygen consumption during experiments. After starting the camera and the data logger, the heating wire was energized to ignite the PMMA sample, and it would be retracted after ignition. The ignition process lasted about $10 \sim 40 \mathrm{~s}$. After ignition, a transition burning stage was required, which enabled the flame to cover the PMMA sphere fully. However, the pre-burning time was minimized to ensure the spherical shape of the sample. Eventually, the capsule was released when the flame was stable. Table 1 lists the initial burning duration $\left(t_{0}\right)$ before the drop for each test.

\section{Normal-Gravity Reference Experiments}

A series of normal-gravity experiments were conducted in the same environmental conditions with microgravity tests except for the gravity level. Normal-gravity tests mainly measured the diminishing diameter and temperature evolutions of the PMMA sphere, which were useful for estimating the heat flux of solid-phase conduction after entering the microgravity condition. Consistent with microgravity experiments, the diameters varied from $10 \mathrm{~mm}$ to $40 \mathrm{~mm}$ were tested in normal-gravity experiments. Differently, one K-type thermocouple with $0.075 \mathrm{~mm}$ bead head diameter was embedded $2 \mathrm{~mm}$ underneath the sphere surface at the bottom side with $\pm 0.25 \mathrm{~mm}$ uncertainty. Another the same thermocouple was placed at the surface to measure the surface temperature, as shown in Fig. 1(b). The surface thermocouple was fixed on the sample holder, which was slowly moved to allow the thermocouple to always contact with the spherical surface. The response time is estimated to $0.34 \mathrm{~s}$ when temperature increases from $38^{\circ} \mathrm{C}$ to $427{ }^{\circ} \mathrm{C}$. The spherical PMMA samples were vertically held $10 \mathrm{~cm}$ above the ground. The PMMA sphere and the sample holder were placed on an electronic mass balance (Sartorius BL310) with an accuracy of $0.01 \mathrm{~g}$ to measure the mass change of the PMMA sphere. A heating wire was used to ignite the sample from the bottom and moved away once the sample was ignited. Besides, a digital camera (Nikon D7200, 30fps) was placed normal to the centerline of the PMMA sphere for recording the overall burning process.

Table 1 The initial burning duration before drop in all microgravity tests

\begin{tabular}{lll}
\hline $\begin{array}{l}\text { Diameter } \\
d(\mathrm{~mm})\end{array}$ & Repeat times & $\begin{array}{l}\text { Pre-drop burning } \\
\text { duration } t_{0}(\mathrm{~s})\end{array}$ \\
\hline 10 & 2 & 16,34 \\
14 & 1 & 20 \\
16 & 1 & 57 \\
20 & 2 & 11,22 \\
30 & 1 & 54 \\
35 & 1 & 34 \\
40 & 3 & $36,49,65$ \\
\hline
\end{tabular}




\section{Results and Discussions}

\section{Burning and Extinction in Microgravity}

Figure 2 shows the photographic sequences of the burning behaviors in normal gravity and microgravity. As the PMMA sphere has a small solid regression rate in microgravity combustion experiments (Johnston et al. 2017), the diameter of the PMMA sphere is nearly equal to the initial diameter even at the end of experiments. Just before the capsule dropping, a stable flame is established in normal gravity, and the yellow flame is observed, which is caused by soot radiation. After entering the semi-quiescent microgravity condition, the flame responds instantaneously and expands away from the surface of the sphere, as shown in Fig. 2. Meanwhile, the brightness of the flame decreases with time. For a small-sized PMMA sphere (i.e., 10-mm diameter), the bright yellow flame can always be observed until the microgravity test was ended, indicating soot production formed. However, as the diameter of the sphere increased to more than $20 \mathrm{~mm}$, the yellow flame faded gradually, and the flame color became weak blue as time went by. In short, the experimental results show that the spherical flame becomes weaker as the diameter increased.

Figure $3 \mathrm{a}$ and $\mathrm{b}$ show the variation of flame width and height versus time with the PMMA spheres diameter of 10
$40 \mathrm{~mm}$, respectively. Note that the flame width in Fig. 3a refers to the largest flame width at the lower hemisphere. Right after the start of the microgravity environment, flame height decreases while the width increases, because of the sudden absences of the buoyancy force. As shown in Fig. $3 \mathrm{a}$, the flame width of the larger PMMA sphere overshoots dramatically compared with the smaller sphere. When the $40 \mathrm{~mm}$ sphere close to its extinction points, the flame becomes unstable which expressed as the fluctuation of the flame width. In contrast, flame widths with smaller PMMA sphere diameters $(10 \mathrm{~mm}$ and $20 \mathrm{~mm}$ ) produce little fluctuations with time. The flame height is appreciably wavered, as shown in Fig. 3b. Specifically, the flame height of the PMMA sphere with smaller diameters $(10 \mathrm{~mm}$ and $20 \mathrm{~mm})$ generates less fluctuation and always decreases with time. While the flame height of the sphere with larger diameters $(30 \mathrm{~mm}$ and $40 \mathrm{~mm}$ ) overshoots again with time and generate more random fluctuation. When the cabin is dropped, the mass flux of the larger diameter sphere decreases more abruptly which leads to the flame is near to the extinction. The near-limit flame is more sensitive to the change of environment condition. Besides, there is residual buoyancy in the cabin during the transition of gravity and the fluctuation of flame height is probably attributed to the buoyancy-induced instability. The gas-phase reaction needs several seconds to reach the steady-state, thus the flame will generate more random fluctuation in the height
Fig. 2 Image of the transition of flame from normal gravity to microgravity (see Videos S1)

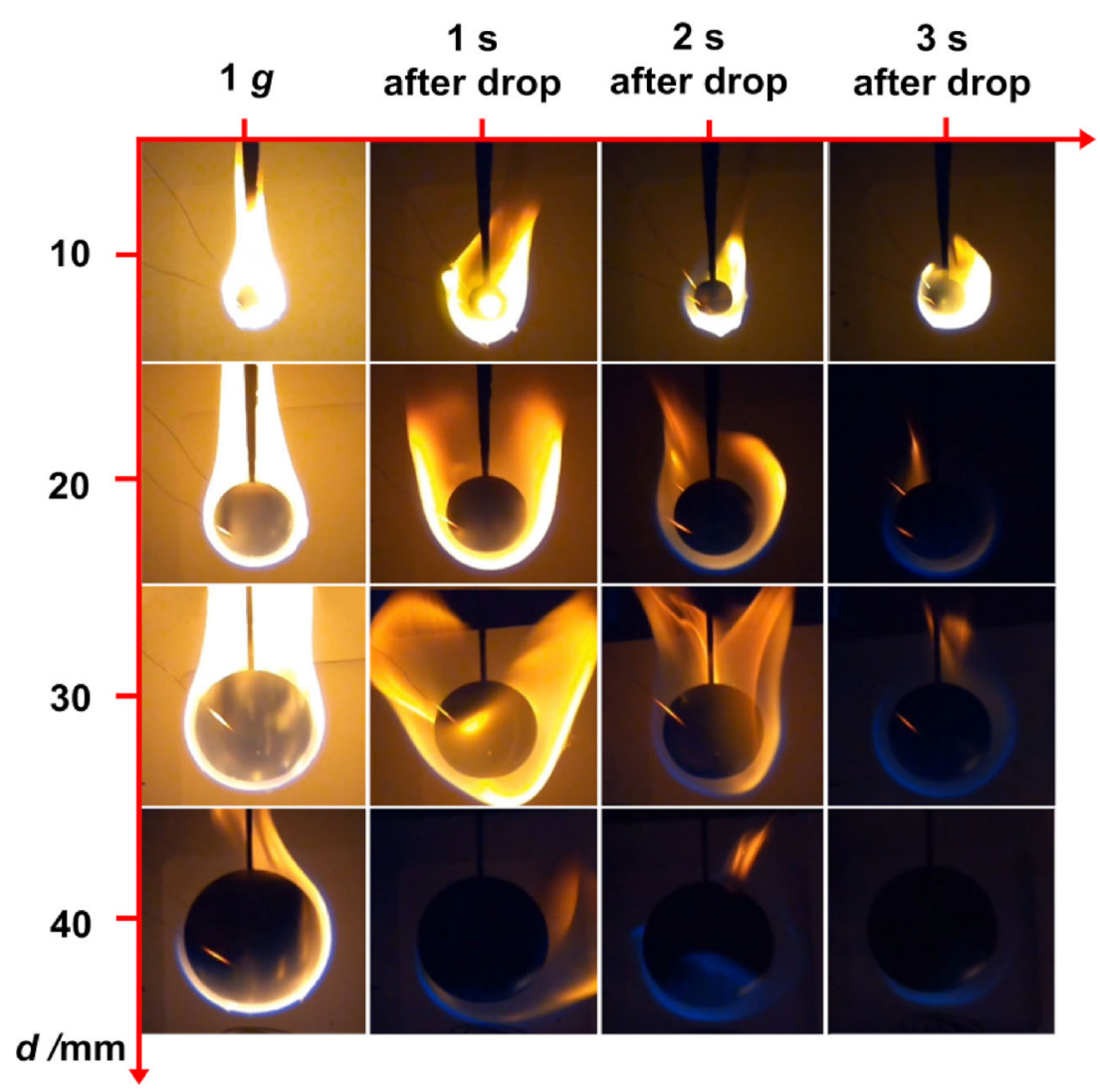


Fig. 3 Variation of flame shape with time during a drop: (a) flame width and (b) flame height

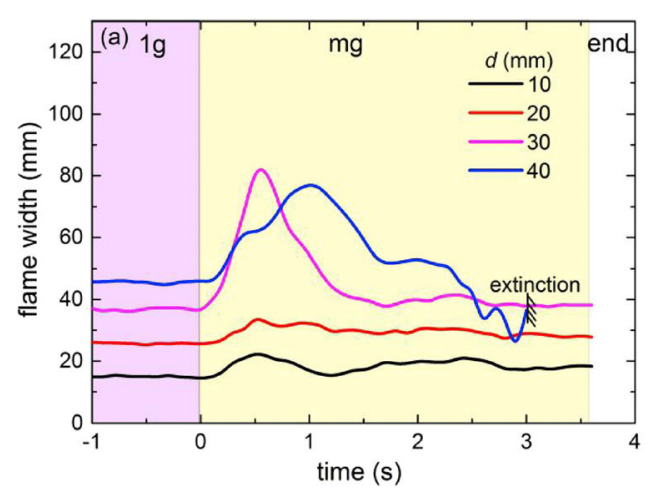

direction to reach a new equilibrium. Compared to Fig. 3 a and $\mathrm{b}$, it is found that the time required for flame height to reach a steady state is longer than it for flame width. The PMMA spheres less than $30 \mathrm{~mm}$ in diameter have no noticeable change within approximately $2.5 \mathrm{~s}$ in the flame width and height, indicating that the flame transits into a relatively stable state. After the transition to the microgravity environment about $3 \mathrm{~s}$, the flame shape is almost stable, the flame height and width are increasingly close, and the flame would eventually shrink into a spherical shape due to the absence of the buoyancy convection, as shown in Fig. 2.

Both the sphere diameter and the pre-drop burning duration have an effect on the flame quenching. Before the flame extinguishes, the flame will oscillate several times, as shown in Fig. 4, and the oscillation frequency is about $2 \mathrm{~Hz}$. Previous researches also reported similar flame oscillations phenomenon when the diffusion flame is at near-limit conditions before extinction (Chan and Tien, 1978; Johnston et al. 2017. Olson et al. 2019). For the $35 \mathrm{~mm}$ diameter sphere with $34 \mathrm{~s}$ pre-burning time, the flame color changes from the yellow to blue, and flame oscillate was observed (Video S2), but the flame was not extinguished as a weak flame still exists until the microgravity time terminated. While when the diameter increases to $40 \mathrm{~mm}$, it will be extinguished within $3.6 \mathrm{~s}$ if the $t_{0}$ is below $50 \mathrm{~s}$ (Video S3). Therefore, the PMMA sphere with a large diameter is more difficult to sustain a flame after entrance the microgravity environment. However, the flame extinguishing not only depends on the sphere diameter, but also the pre-drop burning duration before the microgravity test. When the burning duration $\left(t_{0}\right)$ is larger than $50 \mathrm{~s}$, the flame will not extinguish during $3.6 \mathrm{~s}$ of microgravity time. With the initial burning time increases, the conductive cooling effect decreases due to a small temperature gradient inside the solid fuel. Thus, extinction only can be observed when the initial burning duration before the drop is shorter than $50 \mathrm{~s}$.

\section{Reference Burning Case in Normal Gravity}

The effects of ignition and pre-drop burning duration on the regression of fuel diameter were investigated on the ground to select a reasonable and reliable ignition protocol in the drop-tower test. With the gravity-induced upward buoyancy flow, the burning rate in the horizontal direction is slightly lower than that in the vertical direction, as expected. Thus, to ensure the spherical shape of fuel, the time for ignition and initial burning cannot be too long. To further correct the inevitable change of sphere shape, the equivalent diameter was also calculated based on the real-time measurement of fuel mass $\left(m=\rho_{s} \pi d_{e q}^{3} / 6\right)$. Thus, the equivalent diameter can be expressed as:

$$
d_{e q}=\left(\frac{6 m}{\rho_{s} \pi}\right)^{1 / 3}
$$

Figure 5 shows the square of the height, width, and equivalent diameter of PMMA versus time. The width
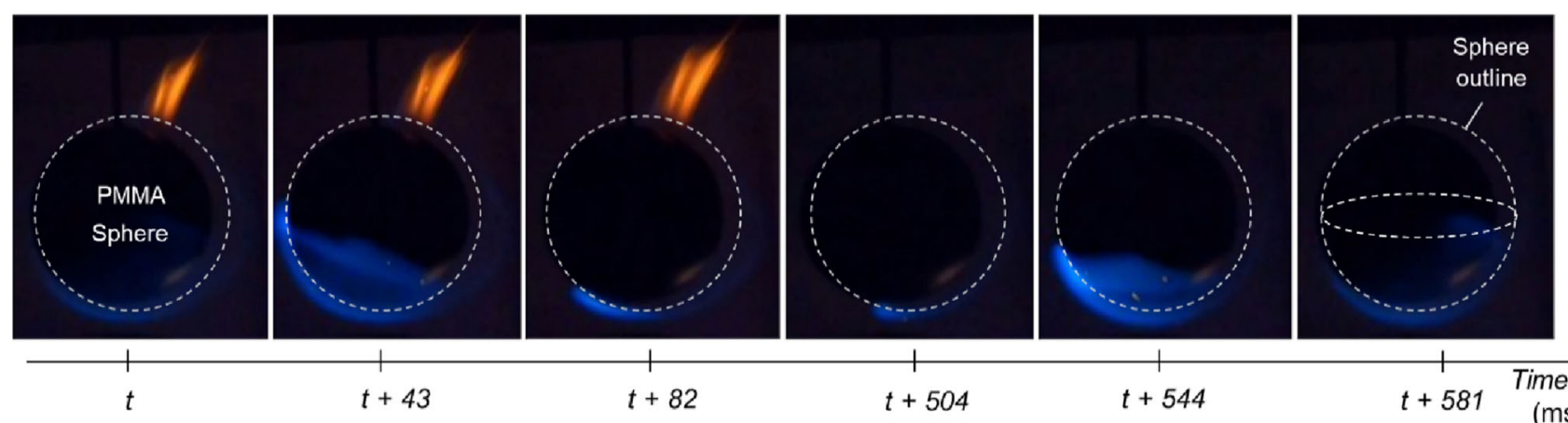

Fig. 4 Flame oscillation near the extinction limit $(d=40 \mathrm{~mm})$ 


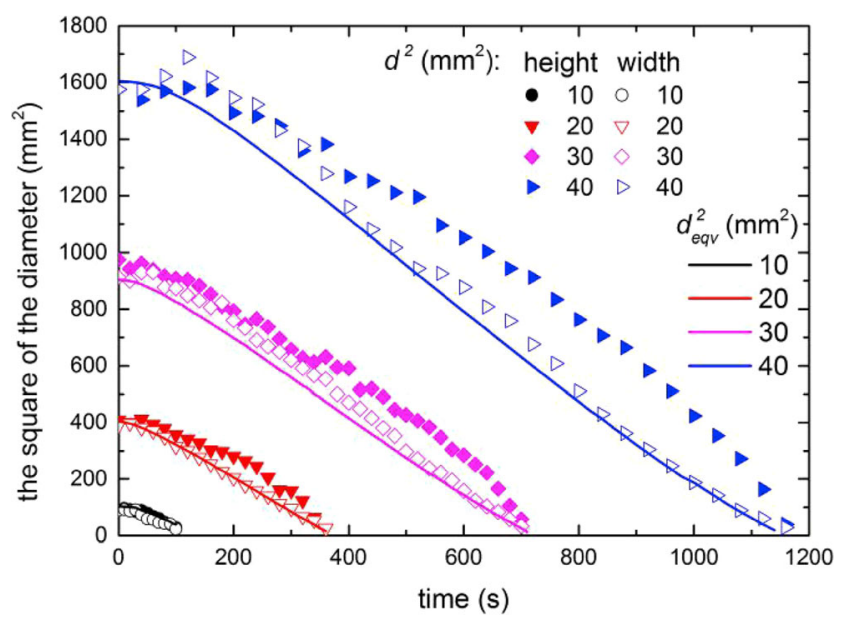

Fig. 5 Time evolution of the square of the height, width, and equivalent diameter of the PMMA sphere in normal gravity

and height of PMMA are measured based on the frame-by-frame analysis of the video. The measurement error is estimated to be $\pm 5 \%$ where the uncertainty is caused by the bubbling effect at the sphere surface. The equivalent diameter has no significant change before ignition. Once ignited, the PMMA would first swell and bubble to cause a small degree of visual expansion (Yang et al. 2000), and afterward, the diameter monotonically decreases. The time required when the equivalent spherical diameter drops by $5 \%$ are $37,55,110,182 \mathrm{~s}$ for diameters of $10,20,30$, and $40 \mathrm{~mm}$, respectively. In other words, the reduction of equivalent diameter of fuel are all less than $5 \%$, and the ratio of width to height is greater than $95 \%$ before the drop. Thus, the diameter and shape of the PMMA sphere have no significant change before the drop. After the stable flame has been established, the square of diameter decreases almost linearly with time, which indicates that the PMMA sphere still roughly obeys d-square law in the normal gravity.

Figure 6(a) shows the surface temperature of the PMMA sphere with diameters of $10,20,30$, and $40 \mathrm{~mm}$, where $t=0$ corresponds to the moment that the PMMA is ignited. The thermocouple data are not corrected by radiation and conduction because the corrections of solid-phase are estimated only about $10 \mathrm{~K}$ at surface temperatures. The pyrolysis temperature $\left(T_{\mathrm{py}}\right)$ of PMMA depends on the heating rate (see TGA curves in Fig. 9(a)), and ranges from $650 \mathrm{~K}$ to $700 \mathrm{~K}$, which also agrees with the literature value of $673 \mathrm{~K}\left(400{ }^{\circ} \mathrm{C}\right)$ (Takahashi et al. 2019). The surface temperature shows a rapid increase during the ignition process and increases above $700 \mathrm{~K}$ within $5 \mathrm{~s}$. In other words, the average surface heating rate is about $50 \mathrm{~K} / \mathrm{s}$ (or $3000 \mathrm{~K} / \mathrm{min}$ ), as shown in Fig. 9(a), and independent of fuel diameter, because of the flame heating. Once the stable flame is established, the surface temperature is about $723 \mathrm{~K}$ ( or $450{ }^{\circ} \mathrm{C}$ ), and as expected, it is near the end temperature of pyrolysis, as shown in Fig. 9(a). The surface temperature has a little fluctuation in the experiments probably due to the bubbling phenomenon. To facilitates the analysis in the present study, it is assumed that the surface temperature of the sphere equals $723 \mathrm{~K}$.

Figure 6(b) shows the in-depth temperature 2-mm below the PMMA sphere with diameters of 10, 20, 30, and $40 \mathrm{~mm}$. The in-depth heating rate is about $3 \mathrm{~K} / \mathrm{s}$ (or $180 \mathrm{~K} / \mathrm{min}$ ), which is much smaller than the surface (Fig. 9(b)). Note that the in-depth heating rate is still greater than that of most TGA tests. Immediately after ignition, the in-depth temperature for the smaller PMMA sphere rises faster. There are two reasons, (1) for the larger sphere, it is harder to heat its inner part due to the substantial thermal inertia; and (2) the solid conduction heat flux is stronger for the smaller sphere because of the curvature effect. Once exceeding about $670 \mathrm{~K}$, the measured in-depth temperature rises rapidly with a strong bubbling process, and the thermocouple may get detached.

More importantly, Fig. 6 shows a significant time lag between the surface and in-depth, which can cause a time variation of the conductive heat loss $\left(\dot{q}_{c o n d, s}^{\prime \prime}\right)$ into the sphere. Thus, by changing the initial burning duration before free fall, the net heat flux on the fuel surface will be varied, which affects the following burning and extinction behaviors in microgravity.
Fig. 6 Thermocouple measurements in normal gravity, (a) surface of PMMA surface, and (b) 2-mm below the sphere where $\mathrm{t}=0$ corresponds to the moment that the PMMA is ignited
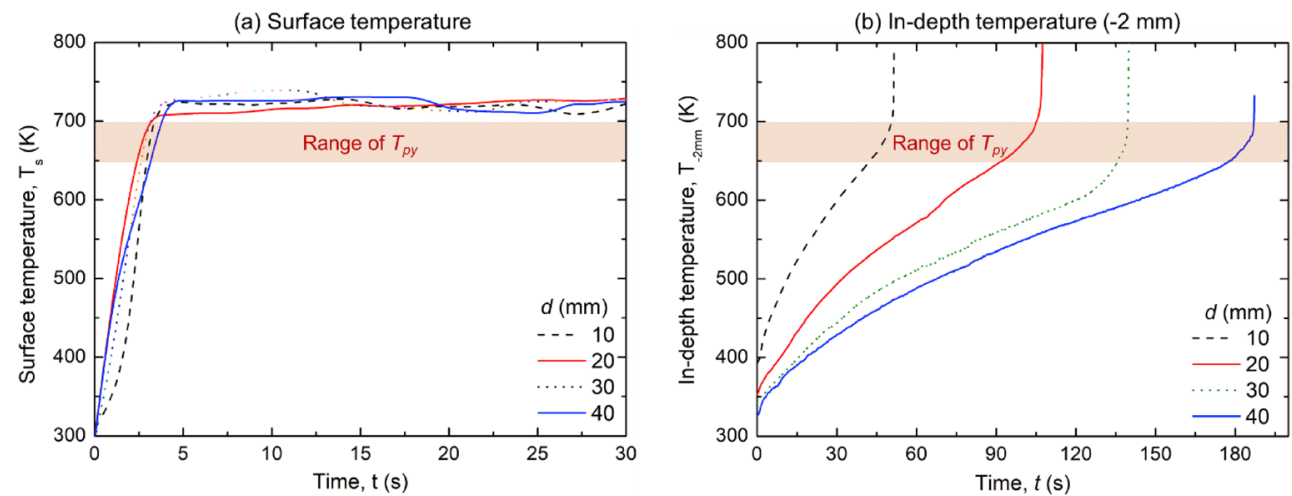


\section{Heat Transfer Analysis}

By choosing the control volume on the surface of the solid sphere (Fig. 7a), the transient energy conservation can be expressed as:

$$
\rho c_{p} \frac{d T_{s}}{d t}+\dot{m}_{F}^{\prime \prime} \Delta h_{p y}=\dot{q}_{c o n d, f}^{\prime \prime}+\dot{q}_{r, f}^{\prime \prime}-\dot{q}_{r e, s}^{\prime \prime}-\dot{q}_{c o n d, s}^{\prime \prime} \geq 0
$$

where $c_{p}$ is the specific heat of solid, $T_{s}$ is the surface temperature, $\dot{m}_{F}^{\prime \prime} \Delta h_{p y}$ is the required heat to pyrolyze the fuel, $\dot{q}_{c o n d, f}^{\prime \prime}$ is the conduction heat flux of flame, $\dot{q}_{r, f}^{\prime \prime}$ is the radiant heat flux of flame, $\dot{q}_{r e, s}^{\prime \prime}$ is the surface reradiation heat loss, and $\dot{q}_{c o n d, s}^{\prime \prime}$ is the conductive heat loss into solid fuel, respectively.

Without the forced and buoyancy flow, the heat transfer from the flame sheet to the solid fuel is controlled by the heat conduction $\left(\dot{q}_{c o n d, f}^{\prime \prime}\right)$. As a function of fuel diameter (Armstrong et al. 2006), this flame conductive heating can be approximated by the steady-state solution as

$\dot{q}_{c o n d, f}^{\prime \prime} \approx k_{g} \frac{\left(T_{f}-T_{p y}\right)}{r_{s}{ }^{2}\left(\frac{1}{r_{s}}-\frac{1}{r_{f}}\right)}=k_{g} \frac{\left(T_{f}-T_{p y}\right)}{r_{s}\left(1-\frac{1}{F S R}\right)}$

where the $k_{g}$ is the conductivity in the gas phase, and $r_{s}$ is the radius of the spherical fuel. Instead of using the surface temperature measured in normal gravity base tests, the pyrolysis temperature is employed as the surface temperature of burning PMMA sphere in microgravity, because the surface temperature decreases with the gravity condition changed (Armstrong et al. 2006). Although the flame temperature also reduced because of the diluted soot concentration, the temperature difference $\left(T_{f}-T_{p y}\right)$ between the flame and solid surface is roughly a constant, due to $T_{f} \gg T_{p y}$. The flame stand-off ratio $(F S R)$ is the ratio of flame diameter $\left(d_{f}\right)$ to solid diameter $\left(d_{s}\right)$.

$F S R=\frac{d_{f}}{d_{s}}=\frac{\ln (1+B)}{\ln [(1+\nu) / \nu]}$

where $\nu$ is the air to fuel stoichiometric mass ratio. The value of FSR is also roughly a constant (Awasthi et al. 2014), because the mass transfer number $(B)$ is mainly controlled by material and environmental parameters that have a small variation. Thus, the conductive heat flux from the flame will decrease with the solid fuel diameter (Fig. 7b). On the other hand, the radiation heat flux from the flame $\left(\dot{q}_{r, f}^{\prime \prime}\right)$ also slightly decreases as the solid fuel diameter increases, because the soot concentration decreases as the flame becomes bluer.

For the cooling effect on the fuel surface, the reradiation heat flux to the environment can be calculated as

$\dot{q}_{r e, s}^{\prime \prime}=\varepsilon \sigma\left(T_{p y}^{4}-T_{\infty}^{4}\right)$

which is almost constant for different fuel diameters, because of the same fuel and same pyrolysis temperature. Thus, the quenching effect, caused by the fuel diameter, is dominated by the solid conduction, especially for thermally thick fuels (Ito et al. 2005).

Based on the thermocouple measurements of the surface temperature $\left(T_{s} \approx T_{p y}\right)$ and the in-depth temperature $\left(T_{i n}\right)$, the conductive cooling from the surface into the solid sphere $\left(\dot{q}_{\text {cond }, s}^{\prime \prime}\right)$ can be estimated by an approximate transient solution as

$\dot{q}_{\text {cond }, \mathrm{s}}^{\prime \prime} \approx k_{s} \frac{T_{s}-T_{\text {in }}}{\delta}\left(1-\frac{\delta}{r_{s}}\right)+\frac{V_{s h}}{A_{s}} \rho c_{p} \frac{d T}{d t}$

where $\delta$ is the depth of the embedded thermocouple, $V_{s h}$ is the volume of the sphere shell, $A_{s}$ is the surface area of the PMMA
Fig. 7 Energy conservation at solid fuel surface, (a) principle diagram, (b) surface heat flux vs. fuel diameter, and the net heat flux at extinction limits (a)

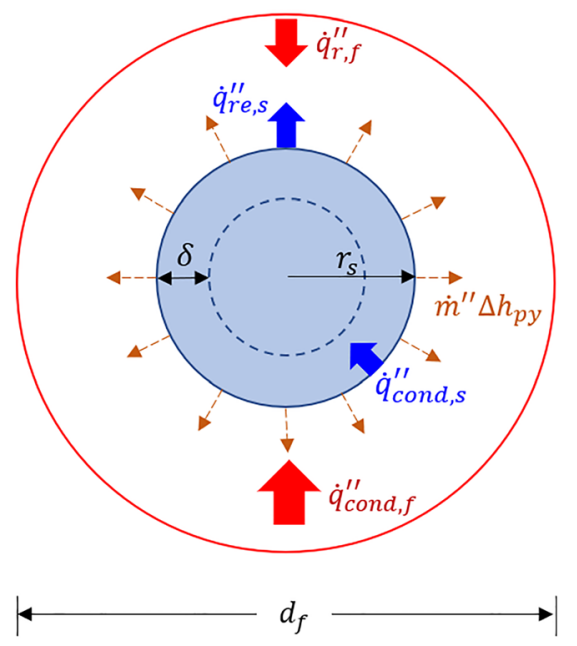

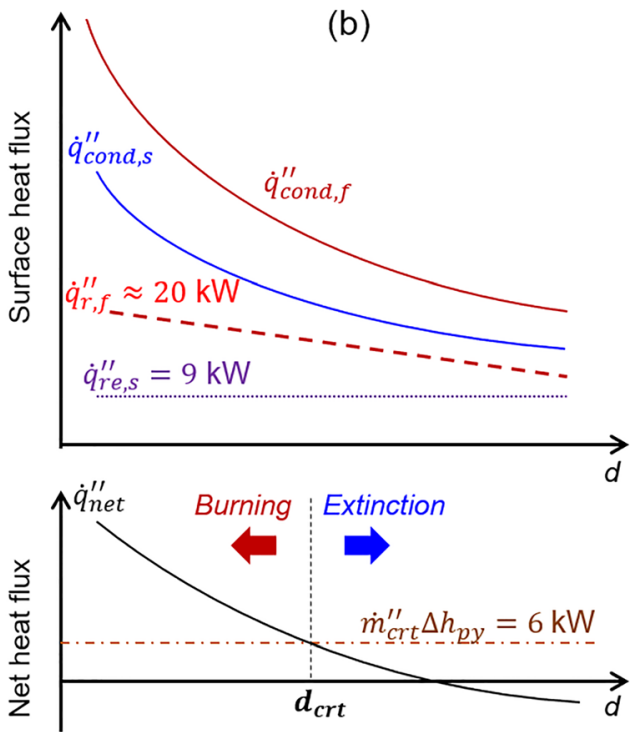


sphere. Figure 8 shows the estimated $\ddot{q}_{c o n d, s}^{\prime \prime}$ where the initial time is defined when the PMMA sphere has the same surface and in-depth temperature, which follows a similar trend in Fig. 7 (b).

For the smaller sphere, the conductive cooling effect is greater at the beginning stage because of the curvature effect, i.e., smaller $r_{s}$ in the first right term of Eq. (6). Moreover, it is faster to heat up the smaller sphere and reduce the temperature difference $\left(T_{s}-T_{i n}\right)$, because of a smaller thermal inertia (the second right term of Eq. (6)). Thus, the decrease of the conductive cooling effect is faster for the smaller sphere. Because the temperature gradient and heat conduction inside the solid are caused by the flame conductive heating, conduction in the solid-phase is always smaller than that in the gas phase $\left(\dot{q}_{\text {cond }, s}^{\prime \prime}<\dot{q}_{c o n d, f}^{\prime \prime}\right.$ ), and they follow the same trend as $\dot{q}_{c o n d, s}^{\prime \prime}=\eta \dot{q}_{\text {cond }, f}^{\prime \prime}$. Thus, we can assume the net conductive heating as

$\dot{q}_{c o n d}^{\prime \prime}=\dot{q}_{c o n d, f}^{\prime \prime}-\dot{q}_{c o n d, s}^{\prime \prime}=(1-\eta) \dot{q}_{c o n d, f}^{\prime \prime}$

which increases with the increase of the flame conductive heating and the decrease of PMMA sphere diameter. Therefore, the extinction was only observed for the large PMMA sphere of the 40-mm diameter.

By ignoring the transient term in Eq. (2), the net heat flux $\left(\dot{q}_{n e t}^{\prime \prime}\right)$ at the fuel surface can be simplified as

$\dot{q}_{n e t}^{\prime \prime}=\left(\dot{q}_{c o n d, f}^{\prime \prime}-\dot{q}_{c o n d, s}^{\prime \prime}\right)+\left(\dot{q}_{r, f}^{\prime \prime}-\dot{q}_{r e, s}^{\prime \prime}\right) \geq \dot{m}_{c r t}^{\prime \prime} \Delta h_{p y}$

where the solid surface should have sufficiently large net heat flux to pyrolyze a minimum amount of fuel gases for maintaining combustion. If the net heat flux below this critical

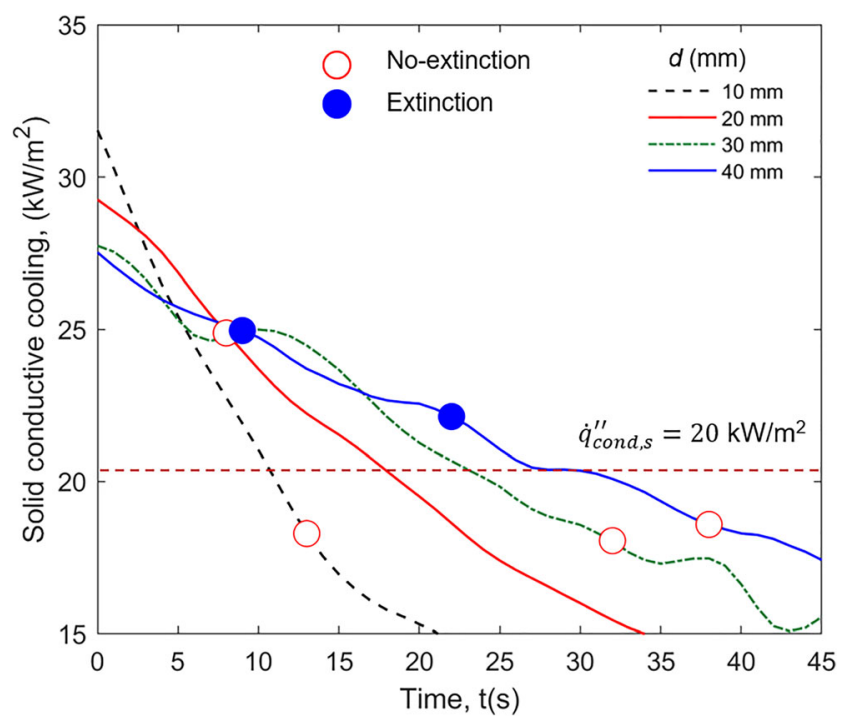

Fig. 8 Calculated heat conduction from the surface to the in-depth as a function of time for PMMA spheres with different diameters $(d), t_{\mu g}$ is the 3.6 s microgravity time value, the flame cannot be sustained. The net heat flux reduced as the solid fuel diameter increases (Fig. 7b). Therefore, a critical diameter to support the flame exists after increasing the sphere diameter.

\section{Extinction Limit}

The mass flux in the semi-quiescent environment for PMMA sphere is similar to the droplet combustion theory, and it can be expressed as:

$$
\dot{m}^{\prime \prime}=\frac{2 k_{g}}{c_{g} d} \ln (1+B)=\kappa \frac{k_{g}}{c_{g}} \ln (1+B)
$$

where $\kappa=1 / r$ is the curvature of fuel and $\mathrm{c}_{\mathrm{g}}$ is the specific heat of gas. Thus, as the increase of diameter $(d)$ or the decrease of curvature $(\kappa)$, the mass flux decreases. When the mass flux is below the critical value of extinction $\left(\dot{m}_{c r t}^{\prime \prime}\right)$ (Quintiere 2006; Rich et al. 2007), the flame cannot be maintained for a sphere larger than the critical diameter $\left(d_{c r t}\right)$. For example, the planar solid fuel can be treated as an extreme type of sphere, whose curvature is 0 . Bhattacharjee et al. (2003) have carried drop tests of planar PMMA samples with thickness varied from $0.0075 \mathrm{~mm}$ to $0.1 \mathrm{~mm}$. The results show that under the same oxygen concentration, the flame extinction happened when the fuel thickness increase. In other words, the thermal inertial effect enhanced with the fuel thickness. In the same way, the larger diameter sphere has greater thermal inertial, which causes extinction.

On the other hand, the decrease of the mass-transfer number $(B)$ can also reduce the mass flux below the critical value. By considering the surface net heat flux, the $B$ number could be expressed as

$$
B=\frac{\Delta h_{c} Y_{\mathrm{O}_{2}}\left(1-X_{r}\right)+c_{g}\left(T_{\infty}-T_{p y}\right)}{\Delta h_{p y}+\frac{\ddot{q}_{c o n d, s}^{\prime \prime}+\left(\dot{q}_{r e, s}^{\prime \prime}-\dot{q}_{r, f}^{\prime \prime}\right)}{\dot{m}^{\prime \prime}}}
$$

Clearly, the increase of solid conductive cooling can reduce the value of $B$ number to lower the mass flux below the extinction limit. According to Fig. 8, the solid conductive cooling decreases with the initial burning duration, so that the later drop could prevent flame extinction, as observed in the drop-tower experiment. Similarly, extinction could also occur if the flame radiation becomes weaker. In other words, for a given fuel diameter, there could be a critical mass-transfer number for extinction $\left(B_{c r t}\right)$.

Previous research estimated that for PMMA plate, the overall heat losses counts for about $80 \%$ of the total flame heat flux, so that the flame would extinguish due to the insufficient heat feedback to the surface (Olson et al. 2004; Zhu et al. 2019). Similar results were also found for cylinder PMMA samples (Armstrong et al. 2006; Olson and T'ien 2000). In 
Table 2 Physical constants used for calculations

\begin{tabular}{llll}
\hline Parameters & Values & Units & References \\
\hline$c_{g}$ & 1.05 & $\mathrm{~kJ} / \mathrm{kg}-\mathrm{K}$ & (Incropera et al. 2013) \\
$c_{p}$ & 1.13 & $\mathrm{~kJ} / \mathrm{kg}-\mathrm{K}$ & (Armstrong et al. 2006) \\
$\Delta h_{c}$ & 26.3 & $\mathrm{MJ} / \mathrm{kg}$ & (Armstrong et al. 2006) \\
$\Delta h_{p y}$ & 1615 & $\mathrm{~kJ} / \mathrm{kg}$ & (Armstrong et al. 2006) \\
$k_{g}$ & 0.1 & $\mathrm{~W} / \mathrm{m}-\mathrm{K}$ & (Incropera et al. 2013) \\
$k_{s}$ & 0.188 & $\mathrm{~W} / \mathrm{m}-\mathrm{K}$ & (Zhu et al. 2019) \\
$T_{\infty}$ & 300 & $\mathrm{~K}$ & - \\
$T_{p y}$ & 670 & $\mathrm{~K}$ & (Takahashi et al. 2019) \\
$X_{r}$ & 0.177 & - & (Rangwala et al. 2008) \\
$Y_{\mathrm{O}_{2}}$ & 0.233 & - & - \\
$\varepsilon$ & 0.85 & - & (Zhu et al. 2019) \\
$\rho$ & 1190 & $\mathrm{~kg} / \mathrm{m}^{3}$ & (Incropera et al. 2013) \\
$\sigma$ & $5.67 \times 10^{-8}$ & $\mathrm{~W} / \mathrm{m}^{2}-\mathrm{K}^{4}$ & (Zhu et al. 2019) \\
$\dot{q}_{r, f}^{\prime \prime}$ & 20 & $\mathrm{~kW} / \mathrm{m}^{2}$ & (Bonnety et al. 2019) \\
$\dot{q}_{r e, s}^{\prime \prime}$ & 9 & $\mathrm{~kW} / \mathrm{m}^{2}$ & Eq. (5) \\
$\dot{q}_{c o n d, s}^{\prime \prime}$ & 20 & $\mathrm{~kW} / \mathrm{m}^{2}$ & Fig. 8 \\
$B_{c r t}$ & 1 & - & Eq. (10) \\
$\dot{m}_{c r t}^{\prime \prime}$ & 3.5 & $\mathrm{~g} / \mathrm{m}^{2}-\mathrm{s}$ & Eq. (9) \\
\hline & & & \\
\hline
\end{tabular}

other words, only a small portion of the flame heat flux may be used to pyrolyze the solid fuel. Table 2 lists parameter values for calculating $B_{c r t}$ when the flame extinguishes for a $40-\mathrm{mm}$ PMMA sphere. By solving Eqs. (9) and (10), $B_{c r t}=1$ and $\dot{m}_{c r t}$ $=3.5 \mathrm{~g} / \mathrm{m}^{2}$-s are found, which is comparable to $\dot{m}_{c r t}^{\prime \prime}=3 \sim$ $5 \mathrm{~g} / \mathrm{m}^{2}$-s of the PMMA plate (Olson et al. 2004; Rich et al. 2007). Note that the estimated $B_{c r t}$ and $\dot{m}_{c r t}{ }^{\prime}$ could change with the fuel diameter, which can be further explored in future microgravity experiments with a longer microgravity duration (e.g., parabolic-flight and space experiments). Moreover, many assumptions are used for parameter values, so that the calculation is only qualitative in nature.

\section{Conclusions}

The flame of PMMA spheres with diameters from $10 \mathrm{~mm}$ to $40 \mathrm{~mm}$ in both in normal gravity and microgravity was investigated to understand the influencing factors of flame extinction in microgravity. Flame extinction was observed for a large PMMA sphere with a 40-mm diameter, if the initial burning duration is less than $50 \mathrm{~s}$ before entering the microgravity environment, which illustrated the curvature effect on conductive heating from the flame. In addition, the large transient temperature gradient of the solid and the high pyrolysis temperature make the extinction of microgravity flame is more sensitive to the conductive cooling and surface radiation, respectively. Increasing the initial burning time can delay or prevent flame extinction in microgravity because of the decreasing conductive cooling effect.

The critical mass flux and the mass-transfer number are adopted to explain the extinction limit for the microgravity flame of spherical fuel. The critical mass flux is estimated as $3.5 \mathrm{~g} / \mathrm{m}^{2} / \mathrm{s}$, and $B_{c r t}$ is about 1 . This work helps understand the curvature effect of solid fuel on flame extinction and material fire safety in the microgravity spacecraft. Future microgravity experiments will be conducted on other spherical fuel materials with detailed numerical simulations to further explore the concept of material fire-safe shape in the spacecraft.

Acknowledgments This work is supported by the National Natural Science Foundation of China (No. U1738117 and 51876183), and by the Strategic Priority Research Program on Space Science, the Chinese Academy of Sciences, under grant Nos. XDA04020410 and XDA04020202-10.

\section{Appendix}

The thermal analysis was applied to the PMMA sample using PerkinElmer STA 6000 Simultaneous Thermal Analyzer. The PMMA sample was heated at the nitrogen gas environment, where the flow rate was $100 \mathrm{~mL} / \mathrm{min}$. The initial mass of PMMA sample was about $4 \mathrm{mg}$, which were heated at two constant rates of 10 and $50 \mathrm{~K} / \mathrm{min}$. Figure 9(a) shows the normalized mass-loss rate vs. temperature at both heating rates. For the pyrolysis in a larger heating rate, it needs a higher temperature to reach a certain mass-loss rate. In other 
words, the pyrolysis temperature increases with the heating rate. Figure 9(b) shows the temperature increase rate (or the heating rate in $\mathrm{K} / \mathrm{min}$ ) of the PMMA surface and in-depth during the experiment with respect to Fig. 6. Clearly, the heating rates of PMMA within the flame were significantly larger than the TG tests. Thus, $670 \mathrm{~K}$ is a reasonable pyrolysis temperature for such a large heating rate in the real-scale experiments.
Fig. 9 (a) DTG curves of PMMA at the heating rates of 10 and $50 \mathrm{~K} / \mathrm{min}$, and (b) the heating rate at the surface and $2 \mathrm{~mm}$ beneath the surface of PMMA sphere with $10-\mathrm{mm}$ and 40-mm diameters
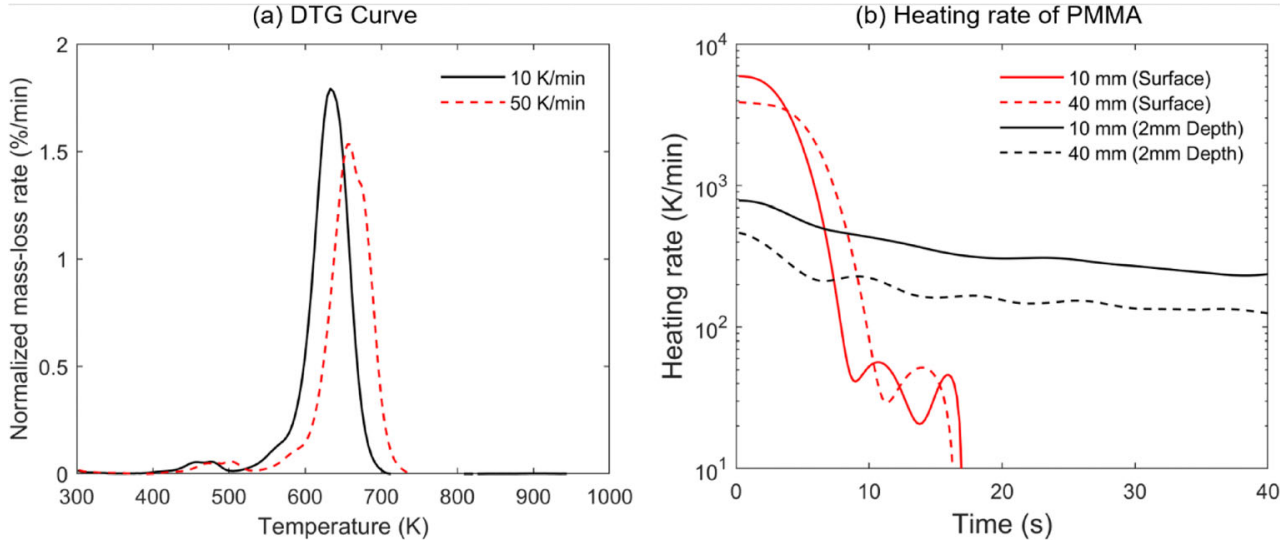

\section{References}

Armstrong, J.B., Olson, S.L., T'ien, J.S.: Transient model and experimental validation of low-stretch solid-fuel flame extinction and stabilization in response to a step change in gravity. Combust. Flame. 147, 262-277 (2006). https://doi.org/10.1016/j.combustflame.2006.09.007

Awasthi, I., Pope, D.N., Gogos, G.: Effects of the ambient temperature and initial diameter in droplet combustion. Combust. Flame. 161, 1883-1899 (2014). https://doi.org/10.1016/j.combustflame.2014. 01.001

Bhattacharjee, S., Altenkirch, R.A.: The effect of surface radiation on flame spread in a quiescent, microgravity environment. Combust. Flame. 84, 160-169 (1991). https://doi.org/10.1016/0010-2180(91) 90045-D

Bhattacharjee, S., Wakai, K., Takahashi, S.: Predictions of a critical fuel thickness for flame extinction in a quiescent microgravity environment. Combust. Flame. 132, 523-532 (2003). https://doi.org/10. 1016/S0010-2180(02)00501-1

Bhattacharjee, S., Simsek, A., Miller, F., Olson, S., Ferkul, P.: Radiative, thermal, and kinetic regimes of opposed-flow flame spread: a comparison between experiment and theory. Proc. Combust. Inst. 36, 2963-2969 (2017). https://doi.org/10.1016/j.proci.2016.06.025

Bobola, R.E., Pate, D.W.: Significant incidents and close calls in human spaceflight: Context for understanding Space Shuttle lessons learned. AIAA SPACE Conference and Exposition 2011. 1-3 (2011). https://doi.org/10.2514/6.2011-7194

Bonnety, J., Guibaud, A., Jalain, R., Matynia, A., Consalvi, J.L., Liu, F., Legros, G.: Probing the local radiative quenching during the transition from a non-smoking to a smoking laminar coflow ethylene/air non-premixed flame. Combustion and Flame. 203, 120-129 (2019). https://doi.org/10.1016/j.combustflame.2019.01.038

Chan, W.Y., Tien, J.S.: An experiment on spontaneous flame oscillation prior to extinction. Combust. Sci. Technol. 18, 139-143 (1978). https://doi.org/10.1080/00102207808946845
De Ris, J.N.: Spread of a laminar diffusion flame. Symp. Combust. 12, 241-252 (1969). https://doi.org/10.1016/S0082-0784(69)80407-8

Delichatsios, M.A., Altenkirch, R.A., Bundy, M.F., Bhattacharjee, S., Tang, L., Sacksteder, K.: Creeping flame spread along fuel cylinders in forced and natural flows and microgravity. Proc. Combust. Inst. 28, 2835-2842 (2000). https://doi.org/10.1016/S0082-0784(00) 80706-7

Dietrich, D.L., Nayagam, V., Hicks, M.C., Ferkul, P.V., Dryer, F.L., Farouk, T., Shaw, B.D., Suh, H.K., Choi, M.Y., Liu, Y.C., Avedisian, C.T., Williams, F.A.: Droplet combustion experiments aboard the international Space Station. Microgravity Sci. Tech. 26, 65-76 (2014). https://doi.org/10.1007/s12217-014-9372-2

Endo, M., T'ien, J.S., Ferkul, P.V., Olson, S.L., Johnston, M.C.: Flame growth around a spherical solid fuel in low speed forced flow in microgravity. Fire. Technol. 56, 5-32 (2020). https://doi.org/10. 1007/s10694-019-00848-2

Friedman, R.: Fire safety in spacecraft. Fire. Mater. 20, 235-243 (1996). https://doi.org/10.1002/(SICI)1099-1018(199609)20:5<235::AIDFAM580>3.0.CO;2-Y

Fujita, O.: Solid combustion research in microgravity as a basis of fire safety in space. Proc. Combust. Inst. 35, 2487-2502 (2015). https:// doi.org/10.1016/j.proci.2014.08.010

Hu, L.H., Delichatsios, M.A., Li, J., Zhang, X.L., Wang, S.F., Huo, R.: Experimental study on diffusive solid combustion behavior during transition from normal- to reduced-gravity. Int. J. Heat Mass Transf. 55, 2035-2043 (2012). https://doi.org/10.1016/j.ijheatmasstransfer. 2011.12.003

Huang, X., Nakamura, Y., Urban, D.: Introduction to special issue on spacecraft fire safety. Fire. Technol. 56, 1-4 (2020). https://doi.org/ 10.1007/s10694-019-00941-6

Ikeda, M.: Effects of gravity on ignition and combustion characteristics of externally heated polyethylene film. Microgravity Sci. Tech. 30, 331-338 (2018). https://doi.org/10.1007/s12217-018-9606-9 
Incropera, F., Lavine, A., Bergman, T., DeWitt, D.: Principles of heat and mass transfer. Wiley (2013)

Ito, A., Kudo, Y., Oyama, H.: Propagation and extinction mechanisms of opposed-flow flame spread over PMMA for different sample orientations. Combust. Flame. 142, 428-437 (2005). https://doi.org/10. 1016/S1540-7489(02)80032-3

Johnston, M.C., James, S.T., T'ien, J.S.: Gravimetric measurement of solid and liquid fuel burning rate near and at the low oxygen extinction limit. Fire Saf. J. 91, 140-146 (2017). https://doi.org/10.1016/j. firesaf.2017.03.027

Law, C.K.: Recent advances in droplet vaporization and combustion. Prog. Energy Combust. Sci. 8, 171-201 (1982). https://doi.org/10. 1016/0360-1285(82)90011-9

Link, S., Huang, X., Fernandez-Pello, C., Olson, S., Ferkul, P.: The effect of gravity on flame spread over PMMA cylinders. Sci. Rep. 8, 120 (2018). https://doi.org/10.1038/s41598-017-18398-4

Migita, T., Yamahata, T., Strempfl, P., Matsuoka, T., Nakamura, Y.: Methodology to achieve Pseudo 1-D combustion system of polymeric materials using low-pressured technique. Fire. Technol. 56, 229-245 (2020). https://doi.org/10.1007/s10694-019-00877-x

Mikami, M., Yoshida, Y., Seo, T., Sakashita, T., Kikuchi, M., Suzuki, T., Nokura, M.: Space-Based Microgravity Experiments on Flame Spread over Randomly Distributed n-Decane-Droplet Clouds: Overall Flame-Spread Characteristics. Microgravity Sci. Tech. 30, 535-542 (2018a). https://doi.org/10.1007/s12217-018-9637-2

Mikami, M., Yoshida, Y., Seo, T., Sakashita, T., Kikuchi, M., Suzuki, T., Nokura, M.: Flame Spread and Group-Combustion Excitation in Randomly Distributed Droplet Clouds with Low-Volatility Fuel near the Excitation Limit: a Percolation Approach Based on Flame-Spread Characteristics in Microgravity. Microgravity Sci. Tech. 30, 419-433 (2018b). https://doi.org/10.1007/s12217-018-9603-z

Nagachi, M., Mitsui, F., Citerne, J.M., Dutilleul, H., Guibaud, A., Jomaas, G., Legros, G., Hashimoto, N., Fujita, O.: Can a spreading flame over electric wire insulation in concurrent flow achieve steady propagation in microgravity? Proc. Combust. Inst. 37, 4155-4162 (2019). https://doi.org/10.1016/j.proci.2018.05.007

Olson, S.L., Ferkul, P.V.: Microgravity flammability boundary for PMMA rods in axial stagnation flow: experimental results and energy balance analyses. Combust. Flame. 180, 217-229 (2017). https://doi.org/10.1016/j.combustflame.2017.03.001

Olson, S.L., Hirsch, D.: Geometry Considerations in Evaluating 0g Materials Flammability Limits for Comparison with NASA Upward Flame Propagation ( Test 1 ) Limits. 41st International Conference on Environmental Systems. 0-9 (2011). https://doi.org/ 10.2514/6.2011-5068

Olson, S.L., Ferkul, P.V., Marcum, J.W.: High-speed video analysis of flame oscillations along a PMMA rod after stagnation region blowoff. Proc. Combust. Inst. 37, 1555-1562 (2019). https://doi. org/10.1016/j.proci.2018.05.080

Olson, S.L., Hegde, U., Bhattacharjee, S., Deering, J.L., Tang, L., Altenkirch, R.A.: Sounding rocket microgravity experiments elucidating diffusive and radiative transport effects on flame spread over thermally thick solids. Combust. Sci. Tech. 176, 557-584 (2004). https://doi.org/10.1080/00102200490276773

Olson, S.L., Hirsch, D.: Geometry Considerations in Evaluating 0g Materials Flammability Limits for Comparison with NASA Upward Flame Propagation ( Test 1 ) Limits. 41st International Conference on Environmental Systems. 0-9 (2011b). https://doi. org/10.2514/6.2011-5068

Olson, S.L., T'ien, J.S.: Buoyant low-stretch diffusion flames beneath cylindrical PMMA samples. Combust. Flame. 121, 439-452 (2000). https://doi.org/10.1016/S0010-2180(99)00161-3

Quintiere, J.: Fundamentals of Fire Phenomena. John Wiley \& Sons, Ltd, London (2006)
Raghunandan, B.N., Mukunda, H.S.: Combustion of polystyrene spheres in air. Fuel. 56, 271-276 (1977). https://doi.org/10.1016/00162361(77)90007-2

Rangwala, A.S., Buckley, S.G., Torero, J.L.: Analysis of the constant Bnumber assumption while modeling flame spread. Combust. Flame. 152, 401-414 (2008). https://doi.org/10.1016/j.combustflame.2007. 09.010

Rich, D., Lautenberger, C., Torero, J.L., Quintiere, J.G., Fernandez-Pello, C.: Mass flux of combustible solids at piloted ignition. Proc. Combust. Inst. 31, 2653-2660 (2007). https://doi.org/10.1016/j. proci. 2006.08 .055

Ross, H.D.: Microgravity combustion : fire in free fall. Academic Press (2001)

Sun, P., Wu, C., Zhu, F., Wang, S., Huang, X.: Microgravity Combustion of Polyethylene Droplet in Drop Tower. Combust. Flame. 222, 18 26 (2020). https://doi.org/10.1016/j.combustflame.2020.08.032

Takahashi, S., Borhan, M.A.F.B., Terashima, K., Hosogai, A., Kobayashi, Y.: Flammability limit of thin flame retardant materials in microgravity environments. Proc. Combust. Inst. 37, 4257-4265 (2019). https://doi.org/10.1016/j.proci.2018.06.102

Takahashi, S., Kondou, M., Wakai, K., Bhattacharjee, S.: Effect of radiation loss on flame spread over a thin PMMA sheet in microgravity. Proc. Combust. Inst. 29, 2579-2586 (2002). https://doi.org/10.1016/ S1540-7489(02)80314-5

Thomsen, M., Huang, X., Fernandez-Pello, C., Urban, D.L., Ruff, G.A.: Concurrent flame spread over externally heated Nomex under mixed convection flow. Proc. Combust. Inst. 37, 3801-3808 (2019). https:// doi.org/10.1016/j.proci.2018.05.055

Urban, D.L., Ferkul, P., Olson, S., Ruff, G.A., James, S.T., Liao, Y.T., Fernandez-pello, A.C., Torero, J.L., Legros, G., Eigenbrod, C., Smirnov, N., Fujita, O., Rouvreau, S., Toth, B., Jomaas, G.: Flame spread: effects of microgravity and scale. Combust. Flame. 199, 122 (2018). https://doi.org/10.1016/j.combustflame.2018.10.012

Vang, C.L., Shaw, B.D.: Evaluation of free-floating droplet acceleration in ISS droplet combustion experiments. Microgravity Sci. Tech. 32, 531-543 (2020). https://doi.org/10.1007/s12217-019-09752-4

Wang, S., Hu, J., Xiao, Y., Ren, T., Zhu, F., Wang, S., Xiao, Y., Zhu, F., Hu, J., Ren, T.: Opposed-flow flame spread over solid fuels in microgravity: the effect of confined spaces. Microgravity Sci. Tech. 27, 329-336 (2015). https://doi.org/10.1007/s12217-015-9419-z

West, J., Tang, L., Altenkirch, R.A., Bhattacharjee, S., Sacksteder, K., Delichatsions, M.A.: Quiescent flame spread over thick fuels in microgravity. Symp. Combust. 26, 1335-1343 (1996). https://doi. org/10.1016/S0082-0784(96)80352-3

Williams, F.A.: Mechanisms of fire spread. Symp. Combust. 16, 12811294 (1977). https://doi.org/10.1016/S0082-0784(77)80415-3

Wu, C., Huang, X., Wang, S., Zhu, F., Yin, Y.: Opposed flame spread over cylindrical PMMA under oxygen-enriched microgravity environment. Fire. Technol. 56, 71-89 (2020). https://doi.org/10.1007/ s10694-019-00896-8

Yang, J.C., Hamins, A., Donnelly, M.K.: Reduced gravity combustion of thermoplastic spheres. Combust. Flame. 120, 61-74 (2000). https:// doi.org/10.1016/S0010-2180(99)00084-X

Zhang, H., Fan, R., Wang, S., Tian, X., Xu, K., Wan, S., Egolfopoulos, F.N.: Extinction of lean near-limit methane/air flames at elevated pressures under normal-and reduced-gravity. Proc. Combust. Inst. 33, 1171-1178 (2011). https://doi.org/10.1016/j.proci.2010.06.027

Zhu, F., Lu, Z., Wang, S., Yin, Y.: Microgravity diffusion flame spread over a thick solid in step-changed low-velocity opposed flows. Combust. Flame. 205, 55-67 (2019). https://doi.org/10.1016/j. combustflame.2019.03.040

Publisher's Note Springer Nature remains neutral with regard to jurisdictional claims in published maps and institutional affiliations. 